\title{
Effects of Social Inclusion and Exclusion in Obesity Surgery Patients: Emotional and Eating Changes after Cyberball Tasks
}

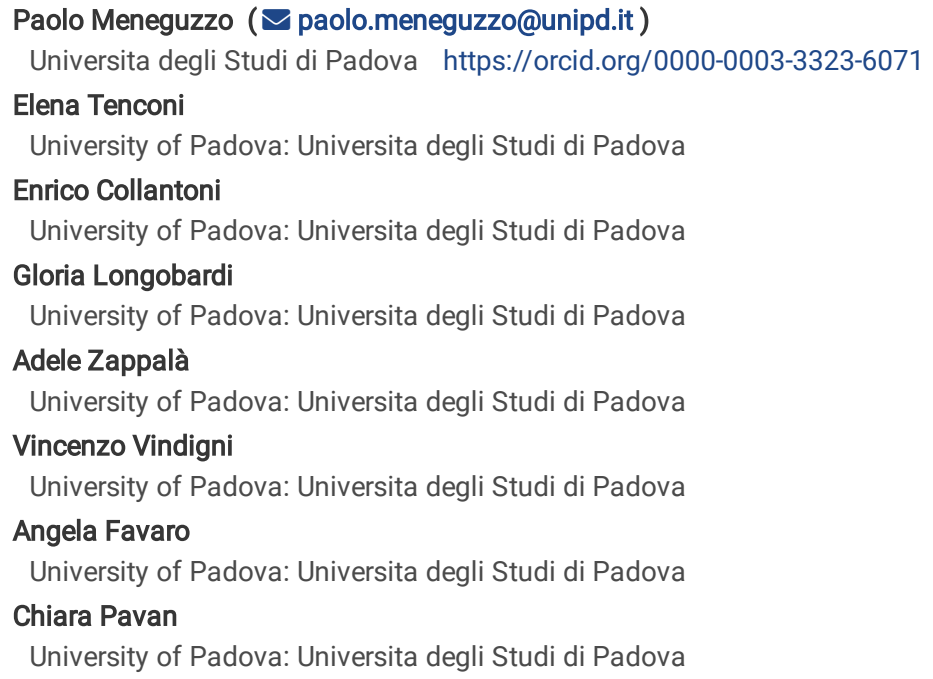




\section{Abstract}

\section{Background}

Social cognition and temperamental and interpretative styles play a significant role in the outcome of bariatric surgery. This study aims to assess how obesity surgery patients evaluate social inclusion and exclusion through a ball-tossing game called Cyberball and examine the influence of early maladaptive schemas on evaluative skills.

\section{Methods}

Thirty-four patients with a history of bariatric interventions for severe obesity and 44 controls were recruited for this study. A psychological evaluation was performed before and after the Cyberball task.

\section{Results}

In the ostracism condition, significant differences were seen across all the patients' fundamental psychological needs with less perceived ostracization ( $p=$ $0.001)$ even if they recognized less interaction via fewer ball tosses. Moreover, the ostracism paradigm resulted in patients experiencing a higher urge to binge $(p=0.010)$ and a higher urge to restrain $(p=0.012)$ than controls. The emotional evaluation led to a modification of the participants feelings in both patients and controls after inclusion or exclusion, but especially after being excluded. As evidenced by the schema domains, the study found a connection between impaired limits-schema domain and the drive to binge.

\section{Conclusion}

The results show how, after bariatric surgery, obese patients cannot differentiate between social inclusion and exclusion and are detached from social interactions. This cognitive style could be reinforced by particular early-maladaptive schemas that could be considered specific therapeutic targets for improving specific interpersonal skills in future research.

Level of evidence: Level III: Evidence obtained from well-designed cohort or case-control analytic studies.

\section{Introduction}

Severe obesity is an increasing worldwide epidemic having relevant impacts on people's daily life, but the efficacy of the treatments is still insufficient (Blüher, 2019). Bariatric surgery is considered one of the most effective treatments, but recent literature has pointed out the lack of knowledge about the elements that could have a positive or a negative effect on its outcome (Blüher, 2019). For example, the psychological effects that weight loss has on severely obese patients are considered only partially positive because various social or interpersonal difficulties can result, such as excess skin excess that remains after bodyweight reduction (Bocchieri et al., 2002; Kubik et al., 2013). After a person undergoes bariatric surgery, social and psychological support is necessary for improving their social interactions and psychological status and reducing the risk of relapse due to excess skin and body image modification (Aarts et al., 2014; Lazar et al., 2009; Meneguzzo et al., 2021; Nickel et al., 2007). However, treatment outcomes could also be compromised due to cognitive aspects. For example, an individual's interpretation of interpersonal interactions, whereby they perceive stigma and aloneness, could stem from their childhood and impact the treatment outcome (Leung et al., 2019; Wilkinson et al., 2017).

Early maladaptive schemas (EMS) are enduring and stable patterns consisting of memories, emotions, cognitions, and bodily sensations that develop in early childhood and affect how a person views themself as an adult in relation to the world (McDermott, 2008; Thimm, 2013). Schemas have been aggregated into four schema domains by recent literature: disconnection and rejection; impaired autonomy and performance; excessive responsibility and standards; and impaired limits. These four schema domains comprise the 18 specific EMSs, and are the result from certain self-defeating, core relational patterns learned in childhood and adolescence (Bach et al., 2018). These schemas are a response to emotional core needs (e.g., love, nurturance, safety, acceptance, and autonomy) being inadequately met by caregivers or significant others, for example. The schemas are repeated in adulthood and are thought to drive a person's interpersonal dealings (see (Taylor et al., 2017) for more information about EMS). Social isolation, mistrust, and abandonment are three EMSs that have been found to play a role in the psychopathology of persons with obesity (Van Vlierberghe et al., 2009). Recent studies have identified EMS as a possible obesity maintaining factor. For instance, research has shown that dysfunctional emotion-avoidant strategies could have been embodied during childhood and could drive someone to use eating behaviors to manage their emotions (Basile et al., 2019). Psychological treatments of EMS and structured schema therapy treatments have been proven to be clinically relevant interventions in patients with obesity (Da Luz et al., 2017; Poursharifi et al., 2011); however, less is known about patients who have already undergone bariatric surgery intervention. For example, no expositive social study has been conducted in the obesity surgery population to evaluate the impact interpersonal dynamics in cognitive schemas of bariatric patients.

In literature, the effects of social interactions-specifically, interpersonal rejection and inclusion-have been evaluated through Cyberball, which is a virtual balltoss task that can manipulate people's experiences by simulating both peer inclusion and ostracism in a standardized way (K.D. Williams \& Jarvis, 2006; Kipling D. Williams et al., 2000). Several general population studies have demonstrated that Cyberball can authentically simulate social ostracism, causing pain and psychological distress (Gunther Moor et al., 2012; Hartgerink et al., 2015). Studies using the Cyberball task to evaluate patients with obesity have demonstrated the possible roles of shame and social isolation in developing and maintaining an over-eating behavior by showing an increase in food intake after being ostracized (Salvy et al., 2011) as well as the increase of the perceived shame (Westermann et al., 2015). A recent meta-analysis has shown that people with obesity report higher interpersonal adversity, higher perceived interpersonal stress, and a lower quality of social life; these findings illustrate the need for psychological interventions targeted toward interpersonal sensitivity (Albano et al., 2019). However, nothing is known about the responses of obesity 
surgery patients at the Cyberball task. Since social skills are the basis of interactions between patients and therapists, it could be essential to investigate whether there are specific patterns that could compromise interpersonal behaviors in obesity surgery patients (Clark et al., 2003).

This study applies the Cyberball paradigm in obesity surgery patients to simulate social ostracism and over-inclusion to look for specific connections with the EMS domains. A deeper understanding of bariatric patients' emotional and interpersonal functioning, especially in regard to early life experiences, might be help tailor specific therapeutic interventions for them. The first hypothesis is that obesity surgery patients show higher sensitivity and have different emotional reactions to being ostracized by peers than controls. Our second hypothesis is that specific EMS could be linked to inclusion and exclusion experiences, which would show a potential role as treatment targets in the OS population.

\section{Methods}

\subsection{Participants}

A group of 34 female subjects with previous severe obesity surgery (OS) were recruited in the outpatient service of the plastic surgery unit of the University Hospital of Padova, Italy. At the time of recruitment, at least two years had passed since their bariatric surgery (post-surgery range was 2-10 years), and all patients had maintained a stable weight and were seeking a contouring surgery. A group of 44 controls $(\mathrm{HC})$ of matched age, gender, and BMI were recruited from the community. The inclusion criteria for both groups were as follows: (1) between 18 and 65 years of age and (2) no severe psychiatric comorbidity, neurological trauma or disorder, or drug addiction. Exclusion criteria for HC were as follows: (1) obesity surgery at any point in their life or (2) extreme weight loss. A trained psychiatrist evaluated all participants for the inclusion or exclusion criteria. All the procedures performed in this study were under the Declaration of Helsinki (1964) and were approved by the local ethics committee. All procedures were carried out with adequate understanding and written consent of the subjects.

\subsection{Materials}

\subsubsection{Computerized task}

Participants were instructed to play a virtual ball-toss game with other two people virtually connected to the game. The Cyberball task was configured as according to previous studies (Hawes et al., 2012), with 30 ball tosses for both conditions: social inclusion and exclusion. The participants received $13 \%$ of the tosses (four ball tosses) during the ostracizing condition and $46 \%$ of the ball-tosses in the over-including condition.

\subsubsection{Questionnaires}

Various self-report questionnaires were used to evaluate specific psychological features that could influence the Cyberball task results. For example, depression was evaluated by the patient health questionnaire (PHQ9), a 9-item self-reported questionnaire that investigates the presence of depression (Kroenke \& Spitzer, 2002). It is considered a well-established instrument for depression screening, where scores $\leq 4$ suggest minimal depression. Cronbach's alpha in the present study was 0.851 . Another questionnaire, the Young schema questionnaire-short form (YSQ-S3), screens for EMS. It is a 90-item self-report questionnaire (Trincas et al., 2014; Young et al., 2005), in which participants are asked to rate a series of statements based on how they felt over the past year. Cronbach's alpha in the present study was 0.869 . Emotional effects of the Cyberball task were evaluated using the positive and negative affect schedule (PANAS), a 20-item self-reported questionnaire widely used to assess both positive and negative affect and their modifications (Watson et al., 1988). The need-threat scale (NTS) is a 21-item questionnaire usually used to indicate ostracism distress (K.D. Williams, 2007). The four dimensions of fundamental psychological needs-belonging, self-esteem, meaningful existence, and control-were used to record feelings of distress or threat. Lower scores on the NTS indicate more significant distress. Finally, each participant was asked to complete two 10-point Likert scale questionnaire, once before and after the Cyberball task. These questionnaires rated how strong his/her urge to binge desire (UTB) or the urge to restrain (UTR) was at that moment.

\subsection{Assessment and procedure}

All participants were randomly assigned to either the exclusion (i.e., ostracism) or over-inclusion condition with the same methodology used in another study (Meneguzzo et al., 2020). Over inclusion was selected for this study instead of standard inclusion based on previous studies demonstrating that people with emotional difficulties need unambiguous scenarios in the Cyberball task to elicit specific cognitive, emotional, or behavioral responses (Weinbrecht et al., 2018). All participants were tested in the same laboratory by the same researchers; the study was conducted in the morning using a 17" laptop. At the beginning of the session, the participants were evaluated for inclusion or exclusion criteria, and then they completed the pretest self-reported questionnaires. In the instructions they received, they were to participate in an online game with two other female participants sitting in nearby rooms; however, in actuality, in the Cyberball paradigm, the two other players are computer-generated. At the end of the testing session, the participants completed the need threat scale (NTS) questionnaire, marked their perceived percentage of tosses received on a Likert scale, answered the Likert-scale questions regarding UTB or UTR, and completed the post-test PANAS. Finally, following the recommendation by the international guidelines regarding deception, all participants were debriefed about the deception created by the Cyberball task and informed of the real reason for the task (Wendler \& Miller, 2004).

\subsection{Statistical analysis}

All data were analyzed using IBM SPSS Statistics 23.0 (SPSS, Chicago, IL, USA). Different independent t-tests were used for the demographic and psychological variables. For instance, the Mann-Whitney test was performed for EMS and the estimation of ball tosses received due to their non-parametric distribution. The pre- and post-Cyberball PANAS and eating behavior urges were tested for repeated measures with a general linear model (GLM). The relationships between EMS domains, NTS subscales, and changes in eating urges (calculated both as pre- and post-tests) were tested with correlation analysis using Spearman's approach. To control for the multi-comparison bias, the Bonferroni correction was used, and only $p$-values $\leq 0.013$ were considered 
significant. The effect sizes were calculated with Cohen's delta. Power analysis showed that a sample size of 10 people for each group was sufficient for a power of 0.90 (Westermann et al., 2015).

\section{Results}

\subsection{Characteristics of the participants}

No differences in age, BMI, and years of education were seen between the OS and HC groups. Demographic and clinical characteristics are reported in Table 1. However, a significant difference in depression $(t=3.311, p=0.002)$ was found between the two groups.

Table 1

Socio-demographic and clinical characteristics of the study sample

\begin{tabular}{|c|c|c|c|c|c|c|c|}
\hline \multirow{3}{*}{ 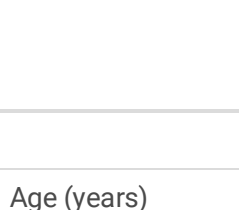 } & \multicolumn{2}{|c|}{$\begin{array}{l}\text { OS } \\
(N=34)\end{array}$} & \multicolumn{2}{|c|}{$\begin{array}{l}\mathrm{HC} \\
(\mathrm{N}=44)\end{array}$} & \multirow[b]{2}{*}{$\mathrm{t}$} & \multirow[b]{2}{*}{$\mathrm{p}$} & \multirow[b]{2}{*}{$d$} \\
\hline & mean & SD & mean & SD & & & \\
\hline & 46.09 & 12.76 & 41.14 & 17.15 & 1.462 & 0.148 & 0.327 \\
\hline Weight (Kg) & 80.65 & 16.32 & 65.98 & 11.41 & \multirow[t]{2}{*}{4.669} & \multirow[t]{2}{*}{$<.001$} & \multirow[t]{2}{*}{1.041} \\
\hline [Range min-max] & \multicolumn{2}{|c|}{ [57.00-138.00] } & \multicolumn{2}{|c|}{ [45.00-92.00] } & & & \\
\hline $\mathrm{BMI}\left(\mathrm{Kg} / \mathrm{m}^{2}\right)$ & 28.79 & 4.95 & 26.91 & 3.85 & \multirow[t]{2}{*}{1.888} & \multirow[t]{2}{*}{0.061} & \multirow[t]{2}{*}{0.424} \\
\hline [Range min-max] & \multicolumn{2}{|c|}{ [19.27-45.06] } & \multicolumn{2}{|c|}{ [18.42-33.30] } & & & \\
\hline $\mathrm{BMI} \min \left(\mathrm{Kg} / \mathrm{m}^{2}\right)$ & 24.71 & 5.72 & 19.43 & 2.14 & 5.050 & $<0.001$ & 1.223 \\
\hline BMI max $\left(\mathrm{Kg} / \mathrm{m}^{2}\right)$ & 46.89 & 8.52 & 30.27 & 4.18 & 11.312 & $<0.001$ & 2.477 \\
\hline Education (years) & 11.00 & 3.34 & 12.60 & 3.65 & 1.420 & 0.100 & 0.457 \\
\hline PHQ9 & 7.20 & 4.15 & 4.55 & 2.46 & 3.311 & 0.002 & 0.777 \\
\hline
\end{tabular}

Table 2 reports the EMS-domain scores for both populations according to the classification proposed by recent literature (Bach et al., 2018). Differences between OS and HC emerged in all the domains: disconnection and rejection (YSQ-DR, $d=1.294)$, impaired autonomy and performance (YSQ-IAP, $d=0.906)$, excessive responsibility and standards (YSQ-ERS, $d=.779$ ), and impaired limits (YSQ-IL, $d=0.861$ ). 
The results of the Young Schema Questionnaire in patients and controls.

\begin{tabular}{|c|c|c|c|c|}
\hline & os & $\mathrm{HC}$ & & \\
\hline & mean SD & $\begin{array}{l}\text { Mean } \\
\text { SD }\end{array}$ & Z & $p$ \\
\hline Disconnection and rejection domain & .736 & .250 & -4.286 & $<.001$ \\
\hline Self-Punitiveness & $(.528)$ & $(.285)$ & & \\
\hline \multicolumn{5}{|l|}{ Vulnerability to harm } \\
\hline \multicolumn{5}{|l|}{ Mistrust/abuse } \\
\hline \multicolumn{5}{|l|}{ Emotional inhibition } \\
\hline \multicolumn{5}{|l|}{ Pessimism } \\
\hline \multicolumn{5}{|l|}{ Emotional deprivation } \\
\hline \multicolumn{5}{|l|}{ Defectiveness/shame } \\
\hline \multicolumn{5}{|l|}{ Social isolation/alienation } \\
\hline Impaired autonomy and performance domain & .617 & .240 & -3.522 & $<.001$ \\
\hline Dependence/incompetence & $(.506)$ & $(.304)$ & & \\
\hline \multicolumn{5}{|l|}{ Vulnerability to harm or illness } \\
\hline \multicolumn{5}{|l|}{ Enmeshment/undeveloped self } \\
\hline \multicolumn{5}{|l|}{ Failure to achieve } \\
\hline \multicolumn{5}{|l|}{ Subjugation } \\
\hline \multicolumn{5}{|l|}{ Abandonment/Instability } \\
\hline \multicolumn{5}{|l|}{ Insufficient self-control } \\
\hline \multicolumn{5}{|l|}{ Pessimism } \\
\hline Excessive responsibility \& standards & .597 & .236 & -3.039 & .002 \\
\hline Subjugation & $(.586)$ & $(.294)$ & & \\
\hline \multicolumn{5}{|l|}{ Self-punitiveness } \\
\hline \multicolumn{5}{|l|}{ Unrelenting standards } \\
\hline \multicolumn{5}{|l|}{ Enmeshment/undeveloped self } \\
\hline \multicolumn{5}{|l|}{ Subjugation } \\
\hline \multicolumn{5}{|l|}{ Pessimism } \\
\hline Impaired limits domain & .847 & .435 & -2.741 & .006 \\
\hline Entitlement/grandiosity & $(.673)$ & $(.435)$ & & \\
\hline \multicolumn{5}{|l|}{ Insufficient self-control/self-discipline } \\
\hline Approval seeking & & & & \\
\hline
\end{tabular}

\subsection{Cyberball results}

In the ostracism condition of the Cyberball paradigm, significant differences between the OS and HC subgroups were found for all the fundamental psychological needs, where OS patients reported less perceived ostracization and subjectively fewer ball tosses received, as well as a significantly greater sense of belonging and higher perception of control than the $\mathrm{HC}$ group. The OS participants reported a correct estimation of ball passes ( $14 \%$ OS, $23 \% \mathrm{HC}, Z=$ $-2.420, p=0.013, d=1.12$ ), but results show that they did not perceive or report an excluded condition. Their reports had mixed results: high belonging and high sense of control with few ball passes and low perception of manipulation.

During the over-inclusion condition, significant differences between the OS and $\mathrm{HC}$ groups were found only in the ability to report a correct estimation of the ball toss. OS patients estimated that they received $15 \%$ of passes, whereas $\mathrm{HC}$ reported that they received $56 \%$ of ball passes $(Z=-5.502, p<0.001, d=3.89)$. Looking within populations, OS patients demonstrated less ability to detect ostracism (i.e., no significant difference between ostracism was perceived between OS participants in the ostracism condition versus the over-including condition) even if they were able to estimate the received number of ball tosses correctly. 
Additionally, there were no differences in self-esteem levels in the OS population based on whether they were in the included versus excluded group. However, there was a significant impact on self-esteem in the HC group based on whether they were included or excluded $(t=-3.475, p=0.001)$. See Table 3 for detailed results of the Cyberball conditions' effects on each group.

Table 3

Cyberball exclusion and overinclusion conditions detection in patients and controls



OS: obesity surgery patient; HC: Healthy Control; SD: Standard Deviation; d: Cohens' $d$.

\subsection{Emotional and eating urges change due to the Cyberball paradigm}

As for the emotional changes, Table 3 and Fig. 1 show reporting of mood changes by both groups. A significant effect of the diagnosis - emotional changes interaction with the GLM analyses for repeated measures was found in the ostracized condition both for the positive subscale $\left(F=7.616, p=.009, \eta^{2}=.192\right)$ and for the negative subscale $\left(F=28.204, p<.001, \eta^{2}=.468\right)$. In the over-included condition, no significant differences were found between both groups (positive: $F=3.228, p=.082, \eta^{2}=.089$; negative: $F=5.373, p=.027, \eta^{2}=.140$ ).

With reference to the UTB and UTR scales, the participants showed no differences in the baseline between ostracized subgroups (UTB: $t(32)=2.127, p=0.044$; UTR: $t(33)=.609, p=0.547$ ) and over-included subgroups (UTB: $t(33)=2.161, p=0.041$; UTR: $t(33)=.216, p=0.830$ ). After the Cyberball paradigm, the selfreported changes in UTB and UTR were evaluated using a GLM for repeated measures: in the ostracism paradigm, the pre-and post-UTB scores demonstrated a significant interaction time $x$ diagnosis $\left(F=7.485, p=.010, \eta^{2}=.190\right)$ as did the the UTR scores $\left(F=7.056, p=.012, \eta^{2}=.181\right)$. In the over included condition, no significant interaction time $x$ diagnosis has been found (UTB: $F=2.628, p=.114, \eta^{2}=.072$; UTR: $F=2.678, p=.111, \eta^{2}=.073$ ). The results are shown in Fig. 2.

\subsection{Correlation analyses}

The correlation analyses for the relationship between the fundamental needs evaluated with the NTS and the EMS domains showed significant results only in the OS patients who were placed in the ostracized condition. Significant relationships were found between NTS-self-esteem and YSQ-ER $(\rho=-.599, p=.013)$, and YSQ-IL $(\rho=-.652, p=.006)$. No significant correlations were found in the HC population in either of the conditions. Upon examining the relationship between schema domains and UTB and UTR, a significant correlation was only found between YSQ-IL and change in UTB scores $(\rho=.735, p=.011)$.

\section{Discussion}

The main goal of this study is to investigate how OS patients perceive a social-exclusion situation and their emotional reaction to this condition, as well as the influence that specific cognitive and emotional styles, called EMS, have on the perception of specific social situations (e.g., ostracism).

Looking at the baseline differences between our subsamples, as expected, due to the inclusion and exclusion criteria to participate in this study, weight history showed a higher BMI in the OS patients, and the depression evaluation showed higher scores in OS patients than HCs.(Kroenke \& Spitzer, 2002). Finally, as suggested by the literature, the results regarding EMS domains show a greater impact of EMS in the OS population. This finding confirms the possible presence of early dysfunctional cognitive schemas developed from early interpersonal experiences that could be influencing the behavior of bariatric patients (Da Luz et al., 2017).

The results demonstrate that OS patients are less aware of the excluded condition because they correctly reported fewer ball passes, higher ostracism scores, and a higher feeling of belonging and control than $\mathrm{HC}$ participants. These results might confirm OS patients' inability to identify negative situations or emotions. Furthermore, the results suggest the presence of a cognitive profile secondary to a specific bias for processing negative interpersonal contact, which has been proposed by previous literature (Dalrymple et al., 2018; Zijlstra et al., 2012). Moreover, the literature has already demonstrated that people with obesity use emotional suppression as a coping strategy in everyday life (Zijlstra et al., 2012), and our data confirm this finding by showing that emotional changes are reduced or opposite if compared to matched controls. The OS sample also showed no difference in impact on self-esteem, whether in the exclusion group or inclusion group. This finding could be viewed as a form of detachment from specific social-based negative experiences. But this detachment is not neutral concerning eating behaviors. Indeed, OS patients reported higher levels of drive to binge or restrain from foods, demonstrating that 
being excluded could affect bariatric patients by inciting a response to focus on food. The effect of food on the improvement of mood levels in obese and overweight patients is a well-known phenomenon (Leehr et al., 2015), but the evaluation of the interpersonal dynamics should be included in this model.

The IL domain is linked specifically to eating behaviors after social exclusion. This domain represents the lack of internal limits, an inability to form long-term goals, and a lack of responsibility to others, and it has already been linked to addictions and food behaviors (Aloi et al., 2020; Basile et al., 2019). Shame and overeating have already been shown to be emotional and behavioral responses to being excluded in obese subjects (Salvy et al., 2011; Westermann et al., 2015). The results of this study extend these previous findings to include patients who have had bariatric surgery. This study also shows which cognitive schemas could be implicated. The sense of self and the understanding of interpersonal boundaries could be the specific targets of interventions to improve social skills in OS patients. Moreover, the presence of cognitive schemas that could be provoked by external events is corroborated by the results of the UTB and UTR scales. Our results show that OS patients present a reaction to stressful social events (like being ostracized) significantly different from that of the $\mathrm{HC}$ peers (even though it was not cognitively perceived), and this reaction translated into eating behaviors. Previous studies have already shown that OS patients try to control stressful events with eating concerns or control. For this reason, these schemas could be considered an essential target of psychotherapy treatments (Moore et al., 2016; Weineland et al., 2012). Indeed, stressful events impact eating behaviors (Salvy et al., 2011), and cognitive and behavioral responses could be targeted as weight maintaining factors. Our data support this idea because it shows that, even after stable weight loss, an exclusion from social interaction could require more effort for OS patients, even if stricter eating controls are reinforced (e.g., OS patients were able to reduce their weight drastically and to keep it stable to receive contouring intervention).

Finally, the participants' expectations should be taken into consideration. Niedeggen et al. (2014) have shown that belonging, meaningful existence, and control in the NTS scale are related to the cognitive expectancy of social involvement. These thoughts and ideas can be described on a continuum ranging from ostracism to inclusion in Cyberball tasks. From this perspective, data from this study could also be interpreted as an expectation by OS patients to be excluded by peers, which could cause the mixed results on the NTS scale after the ostracism paradigm. Our controls have a similar BMI but a different maximum BMI, so they might be exposed to less social exclusion than OS patients. Obesity surgery patients could have developed a defense mechanism from negative social interactions, which is evidenced by their emotional and cognitive responses. This aspect of the research could help confirm the need for a global call to action, which has recently been advocated, because weight bias could elicit pervasive negative attitudes or beliefs, expressed as stereotypes, prejudice, and even open discrimination toward obese or overweight individuals (Cohen \& Shikora, 2020).

For future research, a longitudinal approach and a research-mediated evaluation of schemas could help to establish the effects of obesity, bariatric surgery, and weight loss. Furthermore, clinical effects from improving specific cognitive schemas could augment already promising treatments focused on the management of food cues (Schag et al., 2021).

\section{Strength and limits}

In examining the methodology, the suitable match between samples ( $\mathrm{OC}$ and $\mathrm{HC}$ ) and the choice to use over-inclusion conditions should be considered a strength of our study because provides a strong comparison for the ostracism results. These different scenarios have been demonstrated as more acceptable conditions for clinical populations with impaired social and emotional skills (e.g., borderline personality disorder; (De Panfilis et al., 2016)). A possible limitation involves the scales used due to their self-reported nature, even though they are well-validated measures, or the cross-sectional nature of the study. Moreover, the use of the Cyberball task could be implemented into virtual reality, with a more immersive environment, that could reinforce our results. Finally, the use of a cognitive evaluation to determine the participants' food-related behaviors instead of an authentic evaluation of food behaviors after social exclusion or inclusion could also be considered a limitation of this study that may be overcome in future evaluations.

\section{Conclusions}

In summary, the OS patients seem to be less able to differentiate social inclusion from exclusion as they detach from social interaction or frequent, stressful events. Ostracism is shown to have a stronger link to eating behaviors in OS patients than HCs, indicating that they possibly developed a cognitive mechanism of interpreting interpersonal functioning that could influence the bariatric outcome due to the eating behaviors that could follow social exclusion. The data also demonstrate how EMS could play a role in interpreting the interactions between people, possibly revealing a strategy for intervention. In other words, schema results show that impaired limits (general lack of responsibility to others, internal limits, future goals, or all three) are correlated to eating urges in the OS population, signifying a possible direction for future psychological interventions.

\section{What is already known on this subject?}

Interpersonal difficulties could have negative effects on obesity surgery outcome, and psychological support is suggested to improve the outcomes. Early maladaptive schemas are pervasive self-defeating or dysfunctional themes or patterns of memories, emotions, and physical sensations that have negatively affected obesity surgery outcomes, but studies are lacking.

\section{What this study adds?}

This study adds information about the possible eating behaviors of obesity surgery patients after social exclusion or over-inclusion. Specific cognitive schema domains have been pointed out a possible target for the improvement of the bariatric surgery outcome. 


\section{Declarations}

\section{Declaration of Competing Interest}

The authors declare that they have no competing financial interests or personal relationships that could have influenced the work reported in this paper.

\section{Role of Funding Sources}

This research received no specific grant from any funding agency in the public, commercial, or not-for-profit sectors.

\section{Ethical approval}

All procedures performed in studies involving human participants were in accordance with the ethical standards of the institutional and national research committee, and with the 1964 Helsinki declaration and its later amendments, and were approved by the local ethics committee.

\section{Informed consent}

All procedures were carried out with the adequate understanding and written consent of the subjects.

\section{Author contributions}

PM: conceptualization, methodology, software, formal analysis, investigation, data curation, writing - original draft; ET: conceptualization, methodology, writing - review \& editing, supervision; EC: data curation, writing - review \& editing; GL: investigation; AZ: investigation; VV: resources, project administration, supervision; AF: conceptualization, methodology resources, supervision, project administration; CP: conceptualization, methodology, writing - review \& editing, supervision.

\section{Data availability}

The datasets generated during and/or analysed during the current study are not publicly available due to ethical restrictions to protect the confidentiality of the participants, but are available from the corresponding author on reasonable request.

\section{References}

1. Aarts F, Hinnen C, Gerdes V, Acherman Y, Brandjes D (2014) Coping style as a mediator between attachment and mental and physical health in patients suffering from morbid obesity. Int J Psychiatry Med 47(1):75-91. https://doi.org/10.2190/PM.47.1.g

2. Albano G, Rowlands K, Baciadonna L, Coco G, Lo, Cardi V (2019) Interpersonal difficulties in obesity: A systematic review and meta-analysis to inform a rejection sensitivity-based model. Neurosci Biobehav Rev 107(May):846-861. https://doi.org/10.1016/j.neubiorev.2019.09.039

3. Aloi M, Verrastro V, Rania M, Sacco R, Fernández-Aranda F, Jiménez-Murcia S, De Fazio P, Segura-Garcia C (2020) The Potential Role of the Early Maladaptive Schema in Behavioral Addictions Among Late Adolescents and Young Adults. Front Psychol 10(January):1-10. https://doi.org/10.3389/fpsyg.2019.03022

4. Bach B, Lockwood G, Young JE (2018) A new look at the schema therapy model: organization and role of early maladaptive schemas. Cognitive Behaviour Therapy 47(4):328-349. https://doi.org/10.1080/16506073.2017.1410566

5. Basile B, Tenore K, Mancini F (2019) Early maladaptive schemas in overweight and obesity: A schema mode model. Heliyon 5(9):e02361. https://doi.org/10.1016/j.heliyon.2019.e02361

6. Blüher M (2019) Obesity: global epidemiology and pathogenesis. Nature Reviews Endocrinology 15(5):288-298. https://doi.org/10.1038/s41574-0190176-8

7. Bocchieri LE, Meana M, Fisher BL (2002) A review of psychosocial outcomes of surgery for morbid obesity. J Psychosom Res 52(3):155-165. https://doi.org/10.1016/S0022-3999(01)00241-0

8. Clark MM, Balsiger BM, Sletten CD, Dahlman KL, Ames G, Williams DE, Abu-Lebdeh HS, Sarr MG (2003) Psychosocial Factors and 2-Year Outcome Following Bariatric Surgery for Weight Loss. Obes Surg 13(5):739-745. https://doi.org/10.1381/096089203322509318

9. Cohen R, Shikora S (2020) Fighting Weight Bias and Obesity Stigma: a Call for Action. Obes Surg 30(5):1623-1624. https://doi.org/10.1007/s11695-02004525-0

10. Da Luz FQ, Sainsbury A, Hay P, Roekenes JA, Swinbourne J, Da Silva DC, Da S, Oliveira M (2017) Early maladaptive schemas and cognitive distortions in adults with morbid obesity: Relationships with mental health status. Behavioral Sciences, 7(1). https://doi.org/10.3390/bs7010010

11. Dalrymple KL, Clark H, Chelminski I, Zimmerman M (2018) The Interaction Between Mindfulness, Emotion Regulation, and Social Anxiety and Its Association with Emotional Eating in Bariatric Surgery Candidates. Mindfulness 9(6):1780-1793. https://doi.org/10.1007/s12671-018-0921-4 
12. De Panfilis C, Meehan KB, Cain NM, Clarkin JF (2016) Effortful control, rejection sensitivity, and borderline personality disorder features in adulthood. J Pers Disord 30(5):595-612. https://doi.org/10.1521/pedi_2015_29_226

13. Gunther Moor B, Güroğlu B, de Macks O, Rombouts ZA, van der Molen SARB, M. W., \& Crone EA (2012) Social exclusion and punishment of excluders: Neural correlates and developmental trajectories. Neurolmage 59(1):708-717. https://doi.org/10.1016/j.neuroimage.2011.07.028

14. Hartgerink CHJ, Van Beest I, Wicherts JM, Williams KD (2015) The ordinal effects of ostracism: A meta-analysis of 120 cyberball studies. PLoS ONE 10(5):1-24. https://doi.org/10.1371/journal.pone.0127002

15. Hawes DJ, Zadro L, Fink E, Richardson R, O'Moore K, Griffiths B, Dadds MR, Williams KD (2012) The effects of peer ostracism on children's cognitive processes. European Journal of Developmental Psychology 9(5):599-613. https://doi.org/10.1080/17405629.2011.638815

16. Kroenke K, Spitzer RL (2002) The PHQ-9: A new depression diagnostic and severity measure. In Psychiatric Annals (Vol. 32, Issue 9, pp. 509-515). https://doi.org/10.3928/0048-5713-20020901-06

17. Kubik JF, Gill RS, Laffin M, Karmali S (2013) The impact of bariatric surgery on psychological health. Journal of Obesity, 2013. https://doi.org/10.1155/2013/837989

18. Lazar CC, Clerc I, Deneuve S, Auquit-Auckbur I, Milliez PY (2009) Abdominoplasty after major weight loss: Improvement of quality of life and psychological status. Obes Surg 19(8):1170-1175. https://doi.org/10.1007/s11695-009-9883-x

19. Leehr EJ, Krohmer K, Schag K, Dresler T, Zipfel S, Giel KE (2015) Emotion regulation model in binge eating disorder and obesity - a systematic review. Neurosci Biobehav Rev 49:125-134. https://doi.org/10.1016/j.neubiorev.2014.12.008

20. Leung SE, Wnuk S, Jackson T, Cassin SE, Hawa R, Sockalingam S (2019) Binge Eating, Emotional Eating and Weight Loss Two Years after Bariatric Surgery. Nutrients 11(1625):1-12

21. McDermott N (2008) Early maladaptive schemas, attachment, negative affect and relationship satisfaction

22. Meneguzzo P, Behrens SC, Favaro A, Tenconi E, Vindigni V, Teufel M, Skoda EM, Lindner M, Quiros-Ramirez MA, Mohler B, Black M, Zipfel S, Giel KE, Pavan C (2021) Body Image Disturbances and Weight Bias After Obesity Surgery: Semantic and Visual Evaluation in a Controlled Study, Findings from the BodyTalk Project. Obes Surg. https://doi.org/10.1007/s11695-020-05166-z

23. Meneguzzo P, Collantoni E, Bonello E, Busetto P, Tenconi E, Favaro A (2020) The predictive value of the early maladaptive schemas in social situations in anorexia nervosa. European Eating Disorders Review, September 2019, 1-14. https://doi.org/10.1002/erv.2724

24. Moore M, Hopkins J, Wainwright P (2016) Primary care management of patients after weight loss surgery. BMJ 352(March):1-6. https://doi.org/10.1136/bmj.i945

25. Nickel MK, Loew TH, Bachler E (2007) Change in mental symptoms in extreme obesity patients after gastric banding, part II: Six-year follow up. Int J Psychiatry Med 37(1):69-79. https://doi.org/10.2190/X40R-712P-8J44-0L3H

26. Niedeggen M, Sarauli N, Cacciola S, Weschke S (2014) Are there benefits of social overinclusion? Behavioral and ERP effects in the Cyberball paradigm. Frontiers in Human Neuroscience 8(November):1-8. https://doi.org/10.3389/fnhum.2014.00935

27. Poursharifi H, Bidadian M, Bahramizadeh H, Salehinezhad MA (2011) The relationship between early maladaptive schemas and aspects of identity in obesity. Procedia - Social Behavioral Sciences 30:517-523. https://doi.org/10.1016/j.sbspro.2011.10.101

28. Salvy SJ, Bowker JC, Nitecki LA, Kluczynski MA, Germeroth LJ, Roemmich JN (2011) Impact of simulated ostracism on overweight and normal-weight youths' motivation to eat and food intake. Appetite 56(1):39-45. https://doi.org/10.1016/j.appet.2010.11.140

29. Schag K, Leehr EJ, Meneguzzo P, Martus P, Zipfel S, Giel KE (2021) Food-related impulsivity assessed by longitudinal laboratory tasks is reduced in patients with binge eating disorder in a randomized controlled trial. Sci Rep 11(1):1-12. https://doi.org/10.1038/s41598-021-87231-w

30. Taylor CDJ, Bee P, Haddock G (2017) Does schema therapy change schemas and symptoms? A systematic review across mental health disorders. Psychology Psychotherapy: Theory Research Practice 90(3):456-479. https://doi.org/10.1111/papt.12112

31. Thimm JC (2013) Early maladaptive schemas and interpersonal problems: A circumplex analysis of the YSQ-SF. International Journal of Psychology Psychological Therapy 13(1):113-124

32. Trincas R, Ottaviani C, Couyoumdjian A, Tenore K, Spitoni G, Mancini F (2014) Specific dysphoric symptoms are predicted by early maladaptive schemas. The Scientific World Journal, 2014. https://doi.org/10.1155/2014/231965

33. Van Vlierberghe L, Braet C, Goossens L (2009) Dysfunctional schemas and eating pathology in overweight youth: A case-control study. Int J Eat Disord 42(5):437-442. https://doi.org/10.1002/eat.20638

34. Watson D, Clark LA, Tellegen A (1988) Development and Validation of Brief Measures of Positive and Negative Affect: The PANAS Scales. J Pers Soc Psychol 54(6):1063-1070. https://doi.org/10.4135/9781483398839.n13

35. Weinbrecht A, Niedeggen M, Roepke S, Renneberg B (2018) Feeling excluded no matter what? Bias in the processing of social participation in borderline personality disorder. Neurolmage: Clinical 19(January):343-350. https://doi.org/10.1016/j.nicl.2018.04.031

36. Weineland S, Arvidsson D, Kakoulidis TP, Dahl J (2012) Acceptance and commitment therapy for bariatric surgery patients, a pilot RCT. Obesity Research Clinical Practice 6(1):e21-e30. https://doi.org/10.1016/j.orcp.2011.04.004

37. Wendler D, Miller FG (2004) Deception in the Pursuit of Science. Arch Intern Med 164:597-600

38. Westermann S, Rief W, Euteneuer F, Kohlmann S (2015) Social exclusion and shame in obesity. Eat Behav 17:74-76. https://doi.org/10.1016/j.eatbeh.2015.01.001

39. Wilkinson LL, Rowe AC, Sheldon C, Johnson A, Brunstrom JM (2017) Disinhibited eating mediates differences in attachment insecurity between bariatric surgery candidates/recipients and lean controls. International Journal of Obesity 41(12):1831-1834. https://doi.org/10.1038/ijo.2017.157 
40. Williams KD (2007) Ostracism. Annu Rev Psychol 58:425-452. https://doi.org/10.1146/annurev.psych.58.110405.085641

41. Williams KD, Jarvis B (2006) Cyberball: A program for use in research on interpersonal ostracism and acceptance. Behav Res Methods 38(1):174-180

42. Williams KD, Cheung CKT, Choi W (2000) Cyberostracism: Effects of being ignored over the internet. J Pers Soc Psychol 79(5):748-762. https://doi.org/10.1037/0022-3514.79.5.748

43. Young JE, Pascal B, Cousineau P (2005) Young Schema Questionnaire-Short Form 3 (YSQ-S3). In New York, NY: Schema Therapy Institute

44. Zijlstra H, van Middendorp H, Devaere L, Larsen JK, van Ramshorst B, Geenen R (2012) Emotion processing and regulation in women with morbid obesity who apply for bariatric surgery. Psychology Health 27(12):1375-1387. https://doi.org/10.1080/08870446.2011.600761

\section{Figures}
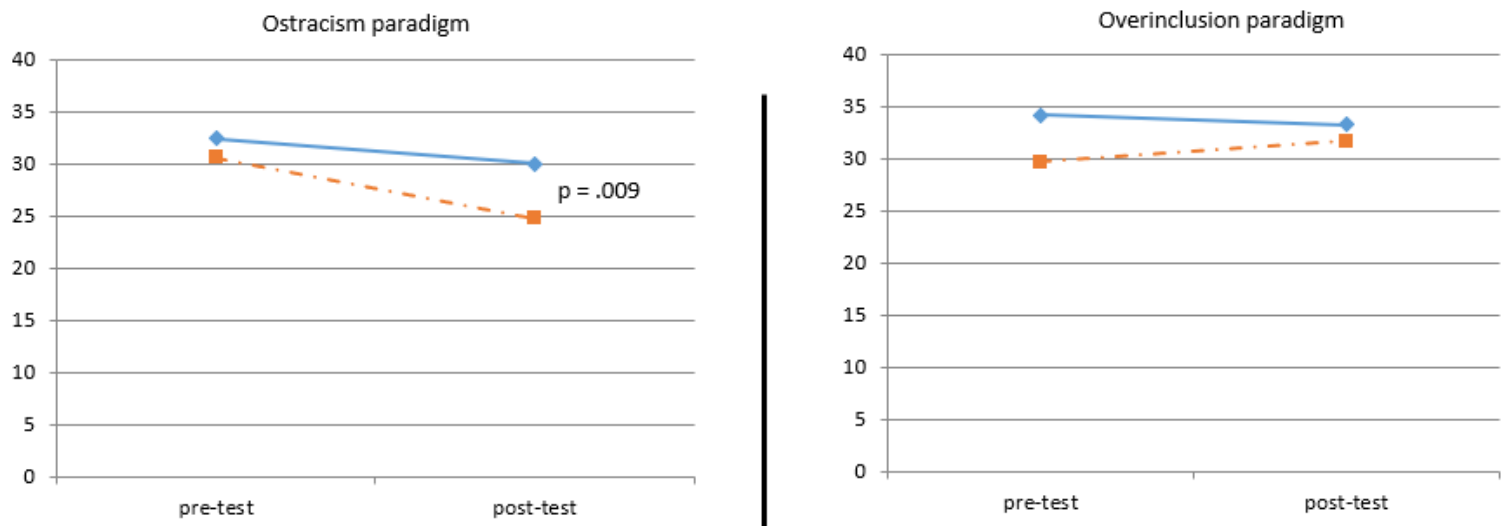

Positive PANAS subscale
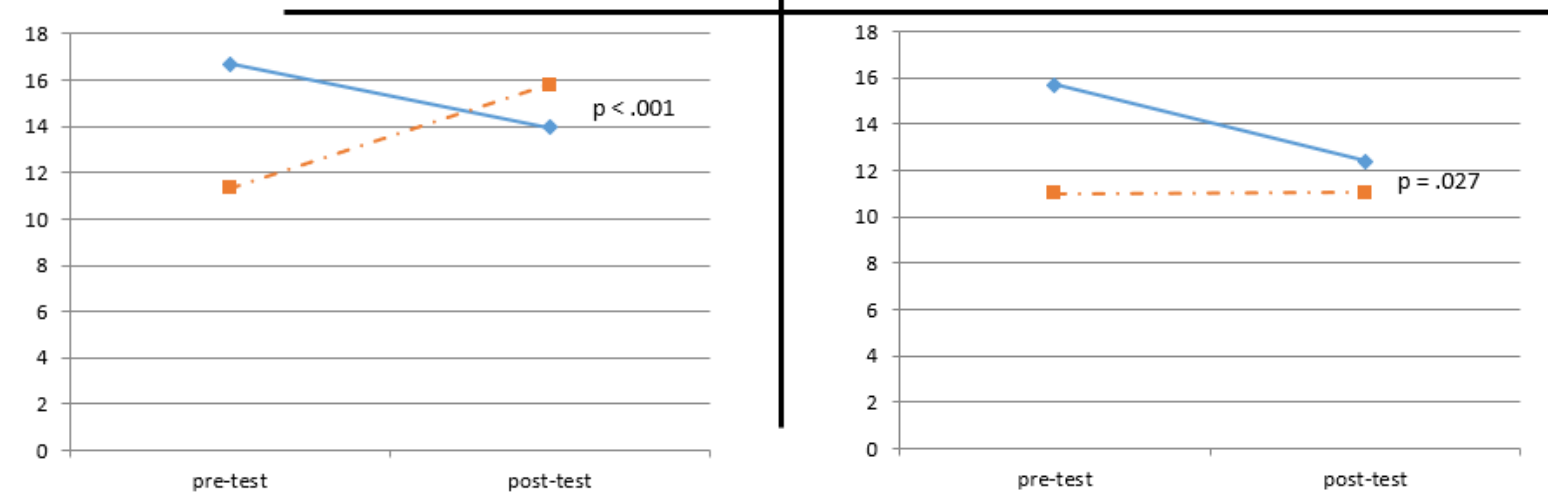

Negative PANAS subscale

\section{Figure 1}

Emotional changes pre-post Cyberball tasks. OS: obesity surgery patients, HC: healthy controls 


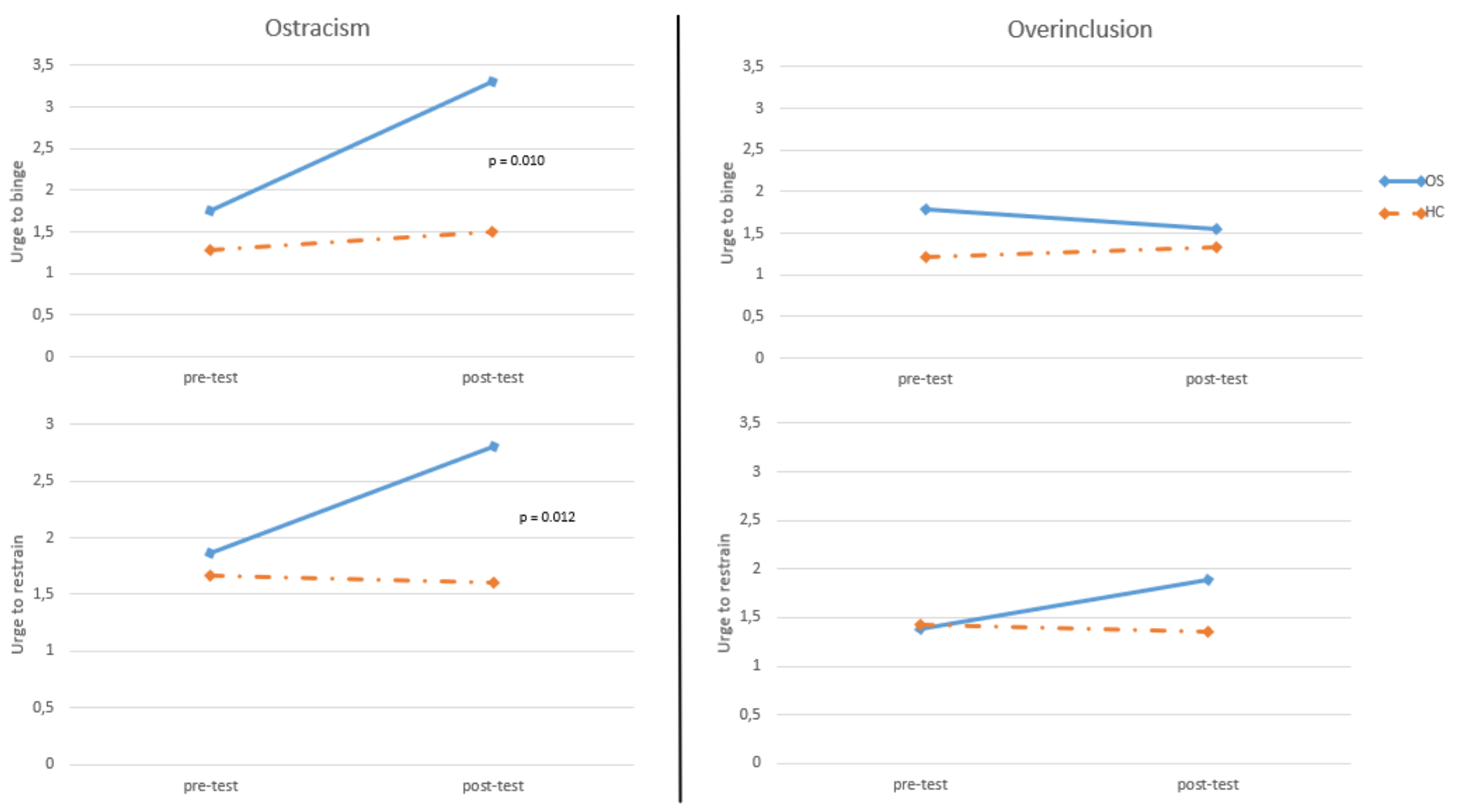

Figure 2

Scores of the urge to binge and the urge to retrain scales. OS: obesity surgery patients, HC: healthy controls 